\title{
Estimates of calf starter energy affected by consumption of nutrients. 2. Effect of changing digestion on energy content in calf starters
}

\author{
J. D. Quigley, ${ }^{*}$ W. Hu, J. R. Knapp, T. S. Dennis, F. X. Suarez-Mena, and T. M. Hill \\ Nurture Research Center, Provimi North America, Cargill Animal Nutrition, Brookville, OH 45309
}

\section{ABSTRACT}

Apparent total-tract digestibility data from 3 published studies with calves from 0 to 4 mo of age were used to evaluate National Research Council (NRC; 2001) estimates of digestible energy (DE) and metabolizable energy (ME) in calf starters (CS). Calves ( $\mathrm{n}=$ $83)$ or pens of calves $(n=24)$ were used in model development. In each study, 48 Holstein bull calves (2-3 $\mathrm{d}$ of age at initiation of each study) were fed varying amounts of milk replacer with CS and water for ad libitum consumption. Calf starters varied in nutrient composition and physical form (pelleted, textured, or mixed with $5 \%$ grass hay and fed as a total mixed ration). Apparent total-tract digestibility was measured at various ages. Feed and feces were collected from 20 calves per trial during 5 -d collection periods during the first $56 \mathrm{~d}$ of each trial. In 2 studies, calves were grouped in pens ( 4 calves/pen) for a second 56-d measurement period. Fecal collections were repeated occasionally during the second period. Total-tract digestibilities (n $=207$ ) of neutral detergent fiber, nonfiber carbohydrates (NFC), crude protein (CP), and fat were used to calculate ME in CS using equations from the 2001 Dairy NRC. Contributions of digestible CP and fat from milk replacer before weaning were estimated using nonlinear regression and removed from estimates of fat and CP digestibility in CS. Digestion of most nutrients in CS and calculated DE and ME in CS were low early in life and increased with increasing cumulative NFC intake. The natural logarithm of cumulative NFC intake, measured from d 0 to the end of each digestibility period, accounted for more variation in CS nutrient digestibilities, DE and ME estimates compared with daily NFC intake or intake of other nutrients, intake of milk replacer, or age of calf. Calculated ME values in CS were similar to those predicted by NRC after calves consumed approximately $15 \mathrm{~kg}$ of cumulative NFC or $28 \mathrm{~kg}$ of cumulative dry matter intake (assuming 53\%

Received July 10, 2018.

Accepted November 27, 2018.

*Corresponding author: jquigley@provimi-na.com
NFC in CS). Current estimates of energy in CS fed to 4 mo of age may overestimate contribution of dry feed to overall energy metabolism in young calves.

Key words: calf, digestion, energy, modeling

\section{INTRODUCTION}

Young dairy calves undergo fundamental changes in the source of nutrients in the first months of life. Maturation of the gastrointestinal tract, including development of fermentative capacity of the reticulorumen, occurs as calves transition from a diet consisting solely of highly digestible colostrum and milk to a postweaning diet consisting primarily of cereal grains and forages (Baldwin et al., 2004; Blum, 2006; Guilloteau et al., 2009). Fermentation of carbohydrates early in life initiates rumen development, which accelerates the time at which calves are prepared for weaning (Warner et al., 1956; Sander et al., 1959).

Energy available from dry feed depends on the caloric content of digestible nutrients and metabolizability of digested energy (NRC, 2001). The extent to which young calves use nutrients from dry feed before and immediately after weaning is not well defined. Studies have reported that digestion of nutrients, but particularly of carbohydrates (including NDF and NFC) are low in very young calves (Terré et al., 2007; Hill et al., 2016b; Chapman et al., 2016; Quigley et al., 2018). The ability to use fibrous feed components depends on development of ruminal fermentation (Hibbs et al., 1956; Stobo et al., 1966), whereas utilization of nonfibrous components such as starch depends on ruminal fermentation as well as intestinal digestion (Harmon et al., 2004; Nozière et al., 2010).

Prediction of digestible energy (DE) and ME in dry feed in current models (NRC, 2001) assumes nutrient digestion in calves is similar to the capacity of mature cows. However, recent research (Terré et al., 2007; Hill et al., 2016b; Dennis et al., 2017, 2018; Quigley et al., 2018) suggests that digestibility of nutrients in calf starter (CS), but particularly of starch and NDF, is poorly developed in young calves and increases with increasing age and CS intake. Further, delayed CS in- 
take due to high levels of preweaning liquid intake may impair nutrient digestion from dry feed (Terré et al., 2007; Hill et al., 2010; Chapman et al., 2016).

Equations to calculate dietary energy in current models of nutrient requirements for calves (NRC, 2001) do not reflect changing digestibility in young calves and, therefore, may overestimate the contribution of CS and other dry feeds to total nutrient supply in the first 4 mo of life. Objective of this study was to evaluate methods to calculate energy values of dry feeds (NRC, 2001) fed to young calves during the first 4 mo of life utilizing estimates of total-tract nutrient digestion.

\section{MATERIALS AND METHODS}

\section{Calves and Management}

Apparent total-tract digestibility (TTD) of nutrients was measured during 3 experiments (Table 1) published previously (Hill et al., 2016b; Dennis et al., 2018; Quigley et al., 2018). In each experiment, 48 newborn Holstein bull calves were transported to the experimental facility and assigned to treatments at 2 to $3 \mathrm{~d}$ of age for 56 (trial 1) or $112 \mathrm{~d}$ (trials 2 and 3 ). Calves were housed in individual pens from 0 to $56 \mathrm{~d}$ (trial 1, 2a, 3a). In experiments 2 and 3 , calves were randomized within treatment on d 57 and moved to group pens (4 calves/ pen) for a second $56 \mathrm{~d}$ (trials $2 \mathrm{~b}$ and $3 \mathrm{~b}$ ). Publication of trial 2 (Quigley et al., 2018) only included trial 2a; trial $2 \mathrm{~b}$ used the same animals and treatments as in trial 2a. Calf was the experimental unit in trials $1,2 \mathrm{a}$, and $3 \mathrm{a}$, and pen was the experimental unit in trials $2 \mathrm{~b}$ and 3b. Experimental treatments and animal management are described elsewhere (Hill et al., 2016b; Dennis et al., 2018; Quigley et al., 2018). In each experiment, a subset of 5 calves/treatment (trials 1, 2a, and 3a) or all pens (trials $2 \mathrm{~b}$ and $3 \mathrm{~b}$ ) were used for digestibility measurements. Samples of feed and feces were collected daily and composited during each 5-d digestibility measurement period. Fecal samples $(n=4 /$ pen $)$ were collected from group pens and representatively sampled to produce one daily composite. Before weaning, chromic oxide (Hill et al., 2016b) was added to milk replacer (MR) and used as a digestion marker. After weaning, feed and fecal concentration of acid insoluble ash (Van Keulen and Young, 1977) was used to estimate digestibility. Each trial used 4 experimental treatments that included varying MR feeding programs, volumes of MR fed, and ages at weaning. Two treatments (Quigley et al., 2018) used high-fiber (NDF $=37 \%$ of DM) pelleted CS (PEL) from 0 to $56 \mathrm{~d}$; all other treatments from 0 to $56 \mathrm{~d}$ used high-starch (starch $=37$ to $43 \%$ of DM) texturized CS (TEX). No forage was fed from d 0 to 56 . From 57 to 112 , CS was mixed with moderate quality chopped grass hay in the ratio of 95:5 in trials $2 \mathrm{~b}$ and $3 \mathrm{~b}$ (TMR). Ingredient and nutrient contents of experimental feeds are in Table 2.

Daily intakes of MR and CS were measured by calf (trials $1,2 \mathrm{a}$, and $3 \mathrm{a}$ ) or pen (trial $2 \mathrm{~b}$ and $3 \mathrm{~b}$ ) and calculated as amount offered minus refusal after $24 \mathrm{~h}$. Average daily dry feed intake during the digestion period and cumulative dry feed intake from the beginning of the trial ( $\mathrm{d}$ 0) through the end of the digestion period were calculated. For trials $2 \mathrm{~b}$ and $3 \mathrm{~b}$, daily dry feed intake was calculated as total intake per pen divided by number of calves per pen. Cumulative dry feed intake was calculated as sum of intake for d 0 to 56 for all calves in a pen during trials $2 \mathrm{a}$ and $3 \mathrm{a}$ plus total intake

Table 1. Description of experiments

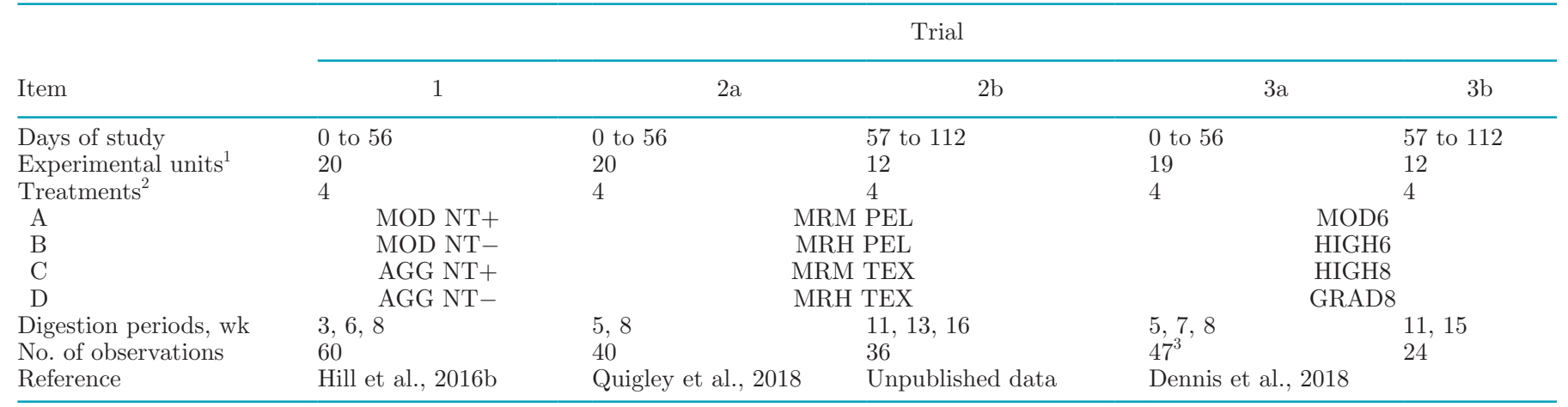

${ }^{1}$ Experimental units were calf in trials $1,2 \mathrm{a}$, and $3 \mathrm{a}$, and pen $(\mathrm{n}=4$ calves/pen $)$ in trials $2 \mathrm{~b}$ and $3 \mathrm{~b}$.

${ }^{2}$ Treatments: trial 1: MOD $=0.66 \mathrm{~kg}$ of milk replacer DM to weaning at $49 \mathrm{~d}$; AGG $=0.66 \mathrm{~kg}$ of milk replacer DM up to $1.31 \mathrm{~kg}$ and weaned at $49 \mathrm{~d} ; \mathrm{NT}+=$ inclusion of functional fatty acids in milk replacer; NT $-=$ absence of functional fatty acids in milk replacer. Trial 2: MRM $=$ $0.66 \mathrm{~kg}$ of milk replacer DM/d and weaned at $49 \mathrm{~d} ; \mathrm{MRH}=0.85$ up to $1.07 \mathrm{~kg}$ of milk replacer DM/d and weaned at $49 \mathrm{~d}$; PEL $=$ high fiber, pelleted calf starter; TEX $=$ high starch, texturized calf starter. Trial 3: MOD6 $=0.66 \mathrm{~kg}$ of milk replacer DM/d and weaned at $42 \mathrm{~d}$; HIGH6 = up to $1.09 \mathrm{~kg}$ of milk replacer DM/d and weaned at $42 \mathrm{~d}$; HIGH8 = up to $1.09 \mathrm{~kg}$ of milk replacer DM/d and weaned at $53 \mathrm{~d}$; GRAD8 = up to $1.09 \mathrm{~kg}$ of milk replacer DM/d and gradually weaned from d 35 to 53 .

${ }^{3}$ Digestion data were collected for only 10 calves during wk 7 . 
of the pen from d 57 to the end of the digestion period. This value was then divided by number of animals in each pen to determine per animal averages.

Description of experiments and experimental units used in model development are in Table 1. Ingredient and nutrient content of diets are in Table 2. Milk replacers fed in trials 1, 2a, and 3a were all-milk protein source with lard as primary fat source. Crude protein concentrations were $27.7,25.1$, and $24.9 \%$ of DM for trials $1,2 \mathrm{a}$, and $3 \mathrm{a}$, respectively, and crude fat concentrations were $18.2,18.6$, and $17.9 \%$, respectively. Highstarch ( $>37 \%$ of DM) TEX were used in trials 1 and 3 and in 2 of 4 treatments in trial 2. Hay used in TMR in trial $2 \mathrm{~b}$ contained $10.3 \% \mathrm{CP}$ and $67.5 \% \mathrm{NDF}$, whereas hay in trial $3 \mathrm{~b}$ contained $6.9 \% \mathrm{CP}$ and $63.5 \% \mathrm{NDF}$.

\section{Model Development and Evaluation}

Digestible nutrients in CS were calculated by multiplying the TTD of each nutrient by content of the nutrient in CS. Digestible NFC fraction in CS (dNFCcs) was calculated as [sugar in CS $(\%$ of DM) $\times 96 \%$ ] + $[\mathrm{SSF}(\%$ of $\mathrm{DM}) \times$ starch digestibility], where SSF $=$ starch + soluble fiber, calculated as NFC - sugar. Digestibility of sugar was not measured and was assumed to be $96 \%$.

Digestible energy (Mcal/kg of DM; DEcs) and ME (Mcal $/ \mathrm{kg}$ of DM; MEcs) in CS were calculated using equations from NRC (2001):

$$
\begin{gathered}
\text { DEcs }(\mathrm{Mcal} / \mathrm{kg})=(\mathrm{dNFCcs} / 100) \times 4.2 \\
+(\mathrm{dNDFcs} / 100) \times 4.2+(\mathrm{dCPcs} / 100) \times 5.6 \\
+(\mathrm{dEEcs} / 100) \times 9.4, \text { and } \\
\text { MEcs }(\mathrm{Mcal} / \mathrm{kg})=(1.01 \times \mathrm{DEcs}-0.45) \\
+0.0046 \times(\text { fat in } \mathrm{CS}-3),
\end{gathered}
$$

\begin{tabular}{|c|c|c|c|c|c|c|c|}
\hline \multirow[b]{2}{*}{ Feed type } & \multirow{2}{*}{$\begin{array}{c}\text { Trial } 1 \\
\text { Textured }\end{array}$} & \multicolumn{2}{|c|}{ Trial $2 \mathrm{a}$} & \multicolumn{2}{|c|}{ Trial $2 \mathrm{~b}$} & \multirow{2}{*}{$\begin{array}{c}\text { Trial 3a } \\
\text { Textured }\end{array}$} & \multirow{2}{*}{$\begin{array}{c}\text { Trial } 3 b \\
\text { TMR }\end{array}$} \\
\hline & & Pellet & Textured & TMR1 & TMR2 & & \\
\hline \multicolumn{8}{|l|}{ Ingredient, $\%$ as fed } \\
\hline Corn, whole & 37.0 & & 37.0 & & 35.2 & 37.0 & 35.2 \\
\hline Oats, oats & 25.0 & & 25.0 & & 23.8 & 25.0 & 23.8 \\
\hline Soybean meal & 23.1 & 18.0 & 23.9 & 17.1 & 22.7 & 23.1 & 21.9 \\
\hline Molasses & 3.0 & 2.5 & 3.0 & 2.4 & 2.9 & 3.0 & 2.9 \\
\hline Alfalfa meal & & & 0.7 & & 0.7 & & \\
\hline Fat & & 2.0 & 0.3 & 1.9 & 0.3 & & \\
\hline Additives $^{1}$ & 4.2 & 6.2 & 4.5 & 5.9 & 4.3 & 4.2 & 4.0 \\
\hline Grass hay & & & & 5.0 & 5.0 & & 5.0 \\
\hline \multicolumn{8}{|l|}{ Nutrient } \\
\hline DM, \% & 88.40 & 87.70 & 86.30 & 88.46 & 87.70 & 87.50 & 87.77 \\
\hline Ash, \% of DM & 7.30 & 6.98 & 6.42 & 7.68 & 7.90 & 6.30 & 6.28 \\
\hline Starch, \% of DM & 43.00 & 9.90 & 41.30 & 9.95 & 38.16 & 37.30 & 35.47 \\
\hline Fat, $\%$ of DM & 3.90 & 4.30 & 3.50 & 4.47 & 3.90 & 3.60 & 3.50 \\
\hline NFC, $\%$ of DM & 55.79 & 36.19 & 58.54 & 27.18 & 52.43 & 54.73 & 54.12 \\
\hline Lignin, $^{2} \%$ of DM & 2.00 & 2.38 & 1.97 & 2.64 & 2.26 & 2.21 & 2.39 \\
\hline NDFIP,, $3 \%$ of DM & 1.09 & 2.41 & 1.06 & 2.86 & 1.64 & 1.40 & 1.70 \\
\hline ADFIP, ${ }^{2,3} \%$ of DM & 0.32 & 0.64 & 0.33 & 0.68 & 0.40 & 0.36 & 0.40 \\
\hline $\mathrm{TDN},{ }^{4} \%$ of $\mathrm{DM}$ & 80.4 & 73.7 & 80.6 & 71.1 & 79.3 & 80.6 & 78.9 \\
\hline $\mathrm{DE},{ }^{4} \mathrm{Mcal} / \mathrm{kg}$ of $\mathrm{DM}$ & 3.66 & 3.33 & 3.63 & 3.25 & 3.61 & 3.67 & 3.59 \\
\hline $\mathrm{ME},{ }^{4} \mathrm{Mcal} / \mathrm{kg}$ of DM & 3.25 & 2.92 & 3.22 & 2.84 & 3.21 & 3.26 & 3.18 \\
\hline
\end{tabular}

where $\mathrm{dCP} c \mathrm{~s}=$ digestible $\mathrm{CP}$ in $\mathrm{CS}$; $\mathrm{dEEcs}=$ digestible ether extract in CS; and dNDFcs = digestible NDF in CS.

Table 2. Ingredient and nutrient composition of diets used in trials 1 to 3

${ }^{1}$ Additives included Ca carbonate, vitamin premix, trace mineral premix, salt, monocalcium phosphate, premix containing decoquinate (Zoetis, Kalamazoo, MI), Mg oxide, premix containing ionophore, limestone, maltodextrin, premix containing diflubenzuron (Clarifly, Central Life Sciences, Schaumburg, IL), and binder.

${ }^{2}$ Nutrient content was estimated using nutrient content of each ingredient.

${ }^{3} \mathrm{NDFIP}=$ neutral detergent insoluble protein; ADFIP $=$ acid detergent insoluble protein.

${ }^{4}$ Energy values at $1 \times$ maintenance; calculated as in NRC (2001). DE $=$ digestible energy. 
Estimates of ME in CS at each digestibility period were also calculated using NRC (2001) equations (MEnrc). Calculated MEnrc was not corrected for depression of ME with intakes above maintenance. Ratio of MEcs to MEnrc (MEratio) was calculated to estimate the time at which estimates of MEcs were similar to MEnrc. An MEratio of $100 \%$ indicated that MEcs was equivalent to MEnrc, suggesting that the ability of the calf to extract ME from CS approached that predicted by NRC (2001).

Before weaning, TTD of CP and fat was partitioned between MR and CS using Proc NLIN in SAS (version 8, SAS Institute Inc., Cary, NC). Models to estimate $\mathrm{CP}$ and ether extract (EE) digestibility from MR were

$$
\begin{gathered}
\mathrm{CPD}=\mathrm{dCPmr} \times \operatorname{mrCP}+\mathrm{dCPcs} \times \operatorname{csCP}, \text { and } \\
\mathrm{EED}=\mathrm{dEEmr} \times \operatorname{mrEE}+\mathrm{dEEcs} \times \operatorname{csEE},
\end{gathered}
$$

where CPD $=$ TTD of $\mathrm{CP}$; $\mathrm{dCPmr}=$ digestibility of $\mathrm{CP}$ in $\mathrm{MR} ; \mathrm{mrCP}=$ percent of $\mathrm{CP}$ intake from $\mathrm{MR}$; $\mathrm{dCP} c s=$ digestibility of $\mathrm{CP}$ in $\mathrm{CS}$; $\operatorname{csCP}=$ percent of $\mathrm{CP}$ in the diet from CS; EED = TTD of EE; dEEmr $=$ digestibility of $\mathrm{EE}$ in $\mathrm{MR}$; $\mathrm{mrEE}=$ percent of $\mathrm{EE}$ intake from MR; dEEcs = digestibility of EE in CS; $\operatorname{csEE}=$ percent of EE in the diet from CS. Coefficients for dCPmr and dEEmr were generated for trials 1, 2a, and $3 \mathrm{a}$, averaged across trial, and 1 value $(81.8 \%$ for dCPmr; $96.8 \%$ for dEEmr) was used to estimate digestible nutrient contributions from MR before weaning. We assumed no contribution of NDF or starch from MR. A sensitivity analysis was conducted for variations in $\mathrm{dCPmr}$ and dEEmr by individually adjusting values for dCPmr and dEEmr from 60 to $100 \%$ and calculating the average MEcs for all observations where MR was fed.

Chemical composition of feeds was determined as in Hill et al. (2016b), Dennis et al. (2018), and Quigley et al. (2018). However, lignin, neutral detergent insoluble protein, and acid detergent insoluble protein were not measured as part of any study. Therefore, these values were estimated based on ingredient composition of CS and tabular values in the NRC feed library (NRC, 2001). Nutrient content of TMR offered during trials $2 \mathrm{~b}$ and $3 \mathrm{~b}$ was calculated as $95 \% \times$ nutrient in concentrate $+5 \% \times$ nutrient in grass hay (Table 2 ).

\section{Statistical Models}

Several statistical models were evaluated and linear mixed models were selected to describe the data (Quigley et al., 2019). Briefly, cumulative NFC intake from CS (ccsNFCI) or natural logarithm of ccsNFCI (lncc-
SNFCI), CS form (PEL, TEX, or TMR), and form $\times$ NFC intake interaction were included as independent variables. Form of starter was included as a fixed effect in the model. Data were analyzed using Proc Mixed of SAS. Age (wk) and MR intake were also evaluated as independent variables. Trial was included in all models as a random effect. Models were reduced when random covariance or random slope were not significant (St-Pierre, 2001). Values in all figures were adjusted as outlined in St-Pierre (2001). Models were constructed for all data $(\mathrm{n}=207)$, during d 0 to $56(\mathrm{n}=147)$ and d 57 to $112(n=60)$.

Because MEratio was more highly related to natural logarithm of cumulative DMI compared with lnccsNFCI, we also evaluated the relationship between MEratio and cumulative DMI using a similar modeling approach (St-Pierre, 2001).

\section{RESULTS}

A total of 207 individual 5-d digestibility measurements were used in the data set, including 147 observations from 83 calves from 0 to $56 \mathrm{~d}$ and 60 observations from group pens during d 57 to 112 . Least squares means of average CS intake during each 5-d digestibility period are shown in Table 3. Apparent TTD of DM, $\mathrm{OM}, \mathrm{CP}, \mathrm{EE}, \mathrm{NDF}, \mathrm{ADF}$, and starch were measured at various ages; descriptive statistics are shown in Table 4. Individual treatment least squares means of TTD within study are available elsewhere (Hill et al., 2016b; Dennis et al., 2018; Quigley et al., 2018).

Natural logarithm of cumulative NFC intake was most highly related to dDMcs, dNFCcs, DEcs, and MEcs. The MEratio was most highly correlated with natural logarithm of cumulative DMI (Quigley et al., 2019).

Models containing multiple independent variables, including MR intake or age of calf, did not significantly improve explanation of dependent variables (data not shown). Therefore, lnccsNFCI was used as the sole independent variable in further model development. Model evaluation statistics using lnccsNFCI and CS form as independent variables are shown in Table 5. Graphic presentation of TTD of DM, CP, EE, NDF, and NFC are shown in Figure 1. Generally, CS form or interaction of form $\times$ lnccsNFCI interactions were significant for TTD measurements (Table 5). For DEcs, MEcs, and MEratio, we also evaluated effects of lnccsNFCI on all data $(\mathrm{n}=207)$, as well as during d 0 to 56 (trials 1a, $2 \mathrm{a}$, and $3 \mathrm{a} ; \mathrm{n}=147$ ) and during $\mathrm{d} 57$ to 112 (trials $2 \mathrm{~b}$ and $3 \mathrm{~b} ; \mathrm{n}=60$ ). Relationship between calf starter DEcs and lnccsNFCI for all data are shown in Figure 2a and d 0 to 56 are in Figure 2b. Similar relationships 
Table 3. Least squares means of calf starter intake in calves fed varying amounts of milk replacer and calf starter during each digestion period

\begin{tabular}{|c|c|c|c|c|c|c|c|c|c|}
\hline Trial & Week & \multicolumn{4}{|c|}{ Treatment $^{1}$} & $\mathrm{SE}$ & \multicolumn{3}{|c|}{$P$-value ${ }^{2}$} \\
\hline \multirow[t]{2}{*}{ Trial 1} & 3 & 0.18 & 0.08 & 0.25 & 0.08 & 0.121 & 0.001 & 0.17 & 0.50 \\
\hline & 8 & 1.92 & 1.58 & 1.84 & 1.80 & 0.121 & & & \\
\hline \multirow{2}{*}{ Trial $2 \mathrm{a}$} & 5 & 0.37 & 0.19 & 0.24 & 0.16 & 0.144 & 0.001 & 0.20 & 0.40 \\
\hline & 8 & 2.08 & 1.60 & 2.02 & 1.72 & 0.144 & & & \\
\hline \multirow{3}{*}{ Trial 3a } & 5 & 0.63 & 0.18 & 0.20 & 0.19 & 0.103 & 0.001 & 0.001 & 0.09 \\
\hline & 7 & 1.91 & 1.34 & & & 0.103 & & & \\
\hline & 8 & 2.78 & 2.17 & 1.92 & 1.97 & 0.103 & & & \\
\hline \multirow[t]{2}{*}{ Trial 3b } & 11 & 2.98 & 2.81 & 3.01 & 2.98 & 0.236 & 0.001 & 0.71 & 0.51 \\
\hline & 15 & 3.50 & 3.59 & 3.81 & 3.98 & 0.236 & & & \\
\hline
\end{tabular}

${ }^{1}$ Treatments: trial 1: $\mathrm{A}=0.66 \mathrm{~kg}$ of milk replacer DM to weaning at $49 \mathrm{~d}(\mathrm{MOD})+$ inclusion of functional fatty acids in milk replacer $(\mathrm{NT}+)$; $\mathrm{B}$ $=\mathrm{MOD}+$ absence of functional fatty acids in milk replacer $(\mathrm{NT}-) ; \mathrm{C}=0.66 \mathrm{~kg}$ of milk replacer DM up to $1.31 \mathrm{~kg}$ and weaned at $49 \mathrm{~d}(\mathrm{AGG})$ $+\mathrm{NT}+; \mathrm{D}=\mathrm{AGG}+\mathrm{NT}-$; trial $2: \mathrm{A}=0.66 \mathrm{~kg}$ of milk replacer $\mathrm{DM} / \mathrm{d}$ and weaned at $49 \mathrm{~d}(\mathrm{MRM})+$ high fiber, pelleted calf starter $(\mathrm{PEL}) ; \mathrm{B}$ $=\mathrm{MRM}+$ high starch, texturized calf starter $(\mathrm{TEX}) ; \mathrm{C}=0.85$ up to $1.07 \mathrm{~kg}$ of milk replacer $\mathrm{DM} / \mathrm{d}$ and weaned at $49 \mathrm{~d}(\mathrm{MRH})+\mathrm{PEL} ; \mathrm{D}=$ $\mathrm{MRH}+\mathrm{TEX}$; trial 3: $\mathrm{A}=0.66 \mathrm{~kg}$ of milk replacer DM/d and weaned at $42 \mathrm{~d} ; \mathrm{B}=$ up to $1.09 \mathrm{~kg}$ of milk replacer DM/d and weaned at $42 \mathrm{~d}$; $\mathrm{C}=$ up to $1.09 \mathrm{~kg}$ of milk replacer DM/d and weaned at $53 \mathrm{~d}$; D = up to $1.09 \mathrm{~kg}$ of milk replacer DM/d and gradually weaned from d 35 to 53 .

${ }^{2}$ Probability of a significant effect of week, treatment $($ Trmt $)$, and week $\times$ treatment interaction $(\mathrm{W} \times \mathrm{T})$.

for MEcs and MEratio are shown in Figures 3a and 3b, and $4 \mathrm{a}$ and $4 \mathrm{~b}$, respectively.

Effects of varying dCPmr and dEEmr on MEcs are shown in Table 6. As predicted digestibility of $\mathrm{CP}$ and $\mathrm{EE}$ in MR increased, predicted digestibility of $\mathrm{CP}$ and $\mathrm{EE}$ in $\mathrm{CS}$ decreased, thereby reducing prediction of energy values in CS.

The MEratio was more highly related to the natural logarithm of calf starter DMI (lnccsDMI) rather than lnccsNFCI. Therefore, we conducted a similar analysis using MEratio as a dependent variable and lnccsDMI as an independent variable.

\section{DISCUSSION}

Rumen development is critical to the calf's ability to use nutrients postweaning. Calves lack the ability to ferment ration components to VFA at birth; this capacity develops with fermentation of ingested carbohydrates to butyrate and propionate that induce changes in rumen papillae and initiate rumen development (Warner et al., 1956; Sander et al., 1959; Stobo et al., 1966). Thus, estimates of energy in CS in young calves should consider rumen development and changing digestion with advancing gastrointestinal maturity. Further, very young calves lack the ability to use starch (Morrill et al., 1970; Guilloteau et al., 1984). Starch utilization appears to be related more to age of the calf rather than intake of starch per se (Guilloteau et al., 2009), although production of amylase appears to be influenced by weaning (Zabielski et al., 1999). Because many CS contain significant amounts of starch and NFC, changing NFC digestion should be important to prediction of $\mathrm{DE}$ and $\mathrm{ME}$ in feeds.

It is noteworthy that cumulative intake of NFC was most highly related to digestibility of most nutrients and to MEcs in our data. Digestion of NDF was highly related to both NDF and NFC intakes. Calf starters generally contain $\geq 60 \%$ carbohydrates; therefore, utilization of carbohydrates is essential to the animal's ability to derive energy from CS. Most of the CS used in these studies were texturized (pellet plus whole corn and whole oats), containing approximately $40 \%$ starch and 6 to $8 \%$ sugar. Thus, digestion of NFC would profoundly affect availability of energy from these feeds. Most of the variation in dNFCcs (Figure 1e) was explained by lnccsNFCI, particularly during the first 56 $\mathrm{d}$ of each study when calves were fed no forage $\left(\mathrm{R}^{2}\right.$ of regression of dNFCcs to lnccsNFCI $=0.85$ and 0.71 for TEX and PEL diets, respectively; Figure 1e). On the other hand, digestibility of most nutrients did not change markedly when calves were fed TMR during d 57 to 112 (trials 2b and 3b), although Hill et al. (2016a) reported that digestion of DM and NDF increased by 10 and $30 \%$ between 11 and 16 wk. However, TTD of CP (Figure 1b) and particularly NDF (Figure 1d) increased from d 57 to 112, possibly due to continued maturation of the rumen and improved fiber digestion with increasing rumen size and intake of more fiber in the TMR.

Previously, we reported that digestion of NFC and NDF increased with increasing cumulative intake of 
NFC and NDF, respectively (Quigley et al., 2018). These data were included in this analysis as trial 2a. This finding suggests that cumulative exposure to fermentable carbohydrate may be an important criterion for determining maturation of the gastrointestinal tract in general and the rumen in particular and is consistent with current theories regarding the importance of fermentable carbohydrate to initiate rumen development (Baldwin et al., 2004; Khan et al., 2016).

Calculated DEcs and MEcs increased with increasing NFC intake and varied by ration form (Table 5 and Figures 2 and 3). Apparently, much of the CS form effect was due to differences between TMR fed during the grower period (d 57 to 112) and either PEL or TEX

Table 4. Mean apparent total-tract digestibility (\%) in calves fed treatments in trials 1 to $3^{1}$

\begin{tabular}{|c|c|c|c|c|c|}
\hline Item & $\mathrm{n}$ & Mean & $\mathrm{SE}$ & Minimum & Maximum \\
\hline \multicolumn{6}{|l|}{ Trial 1} \\
\hline DM & 60 & 81.6 & 0.81 & 68.6 & 90.8 \\
\hline $\mathrm{OM}$ & 60 & 82.7 & 0.78 & 69.7 & 91.7 \\
\hline $\mathrm{CP}$ & 60 & 74.2 & 1.03 & 54.3 & 89.4 \\
\hline Fat & 60 & 90.0 & 0.96 & 62.6 & 98.9 \\
\hline $\mathrm{ADF}$ & 60 & 10.3 & 1.10 & 0.7 & 43.4 \\
\hline NDF & 60 & 16.8 & 1.40 & 1.5 & 54.0 \\
\hline Starch & 60 & 74.6 & 2.54 & 38.2 & 99.8 \\
\hline \multicolumn{6}{|l|}{ Trial 2a } \\
\hline DM & 40 & 76.7 & 1.19 & 54.3 & 89.9 \\
\hline $\mathrm{OM}$ & 40 & 77.4 & 1.16 & 57.0 & 90.4 \\
\hline $\mathrm{CP}$ & 40 & 74.1 & 1.39 & 39.3 & 87.2 \\
\hline Fat & 40 & 89.6 & 0.76 & 76.1 & 97.2 \\
\hline $\mathrm{ADF}$ & 40 & 32.1 & 4.00 & 0.1 & 78.1 \\
\hline $\mathrm{NDF}$ & 40 & 41.7 & 3.06 & 0.4 & 75.8 \\
\hline Starch & 40 & 79.7 & 3.62 & 0.1 & 99.3 \\
\hline \multicolumn{6}{|l|}{ Trial 2b } \\
\hline DM & 36 & 78.9 & 0.89 & 66.4 & 88.2 \\
\hline $\mathrm{OM}$ & 36 & 79.7 & 0.91 & 66.9 & 89.2 \\
\hline $\mathrm{CP}$ & 36 & 81.8 & 0.69 & 73.3 & 89.9 \\
\hline Fat & 36 & 86.6 & 0.61 & 77.8 & 92.3 \\
\hline $\mathrm{ADF}$ & 36 & 55.0 & 2.64 & 12.3 & 75.2 \\
\hline NDF & 36 & 57.4 & 2.84 & 10.6 & 76.6 \\
\hline Starch & 36 & 96.8 & 0.32 & 92.3 & 100.0 \\
\hline \multicolumn{6}{|l|}{ Trial 3a } \\
\hline DM & 47 & 84.4 & 0.63 & 72.0 & 94.7 \\
\hline $\mathrm{OM}$ & 47 & 85.1 & 0.61 & 73.0 & 95.0 \\
\hline $\mathrm{CP}$ & 47 & 81.2 & 0.73 & 65.8 & 92.4 \\
\hline Fat & 47 & 86.8 & 1.07 & 73.2 & 98.3 \\
\hline $\mathrm{ADF}$ & 47 & 32.3 & 2.56 & 1.4 & 62.3 \\
\hline $\mathrm{NDF}$ & 47 & 38.0 & 3.45 & 0.0 & 70.1 \\
\hline Starch & 47 & 79.3 & 3.17 & 43.1 & 99.6 \\
\hline \multicolumn{6}{|l|}{ Trial 3b } \\
\hline DM & 24 & 83.0 & 0.38 & 77.5 & 86.5 \\
\hline $\mathrm{OM}$ & 24 & 84.3 & 0.36 & 80.3 & 88.5 \\
\hline $\mathrm{CP}$ & 24 & 84.4 & 0.47 & 80.0 & 88.5 \\
\hline Fat & 24 & 82.1 & 0.62 & 75.5 & 87.7 \\
\hline $\mathrm{ADF}$ & 24 & 62.7 & 1.02 & 52.1 & 71.4 \\
\hline $\mathrm{NDF}$ & 24 & 62.5 & 0.97 & 49.9 & 70.5 \\
\hline Starch & 24 & 94.2 & 0.41 & 90.5 & 98.1 \\
\hline
\end{tabular}

${ }^{1}$ Total-tract digestion was measured at 3,6 , and 8 wk (trial 1 ); 5 and 8 wk (trial 2a); 11, 13, and 16 wk (trial 2b); 5, 7, and 8 wk (trial 3a); and 11 and 15 wk (trial $3 \mathrm{~b})$. fed during the first $56 \mathrm{~d}$ of the trial. Effect of CS form during the first $56 \mathrm{~d}$ (PEL vs. TEX) was not significant in predicting MEcs (Figure 3b), suggesting that form of CS was less important than NFC content per se during the first $56 \mathrm{~d}$. However, the number of observations of calves fed PEL diets $(\mathrm{n}=20)$ was limited and additional data are required to determine whether form of CS may influence availability of ME from CS. During the period of $\mathrm{d} 57$ to 112, TTD of NDF from the TMR increased from approximately 50 to $60 \%$ (Figure 1d), thereby increasing MEcs (Figure 3a) from CS.

The MEratio was calculated to determine the time at which MEcs met or exceeded MEnrc. In this analysis, MEratio (Figure 4a) varied by ration form. The MEratio increased with increasing ccsNFCI when calves were fed PEL or TEX (Figure 4b) during the first 56 d. However, there was no apparent effect of TMR on MEratio during d 57 to 112 . It should be noted that MEnrc in our analysis was not adjusted for depression in digestibility with intakes above maintenance.

The MEratio reached approximately $100 \%$ when calves consumed at least $15 \mathrm{~kg}$ of NFC (Figure 4b). This suggests that MEnrc overestimated the energy available in CS until gastrointestinal development matured, which may have occurred at approximately 15 $\mathrm{kg}$ of cumulative NFC intake. When calves were fed the TMR during d 57 to 112 , MEratio was similar to $100 \%$, suggesting that calf starter ME predicted using NRC (2001) equations accurately predict ME in TMR containing CS and 5\% forage.

When calves consumed a TEX containing $55 \%$ NFC, $15 \mathrm{~kg}$ of NFC equated to $27 \mathrm{~kg}$ of total CS intake (DM basis), or approximately $30 \mathrm{~kg}$ of CS on an as-fed basis. In cases where calves are fed higher amounts of MR preweaning and cumulative NFC intake is delayed, reduced MEratio may contribute to observed reduction in postweaning BW gain (Chapman et al., 2016; Hill et al., 2016b). Average ages at which MEratio $=100 \%$ (i.e., intake of ccsNFCI $\geq 15 \mathrm{~kg}$ ) varied by trial and treatment. Trial 1 ended at $56 \mathrm{~d}$ and only calves on treatment A consumed $15 \mathrm{~kg}$ of ccsNFCI before the end of the study (d 54). Other calves did not reach ccsNFCI $=15 \mathrm{~kg}$ by the end of the study. For trial 2, ages were $57,63,51$, and $58 \mathrm{~d}$ for treatments $\mathrm{A}, \mathrm{B}, \mathrm{C}$, and $\mathrm{D}$, respectively. For trial 3, ages were 51, 57, 58, and $59 \mathrm{~d}$, respectively.

A common recommendation is to wean calves when CS intake reaches a specific criterion such as consumption of at least $1 \mathrm{~kg}$ of CS/d for 1 or more days (Quigley, 1996; Greenwood et al., 1997). Our data suggest that both intake and digestibility are essential considerations in preparation for weaning. Our data suggest that cumulative intake may be a more appropriate cri- 
QUIGLEY ET AL.

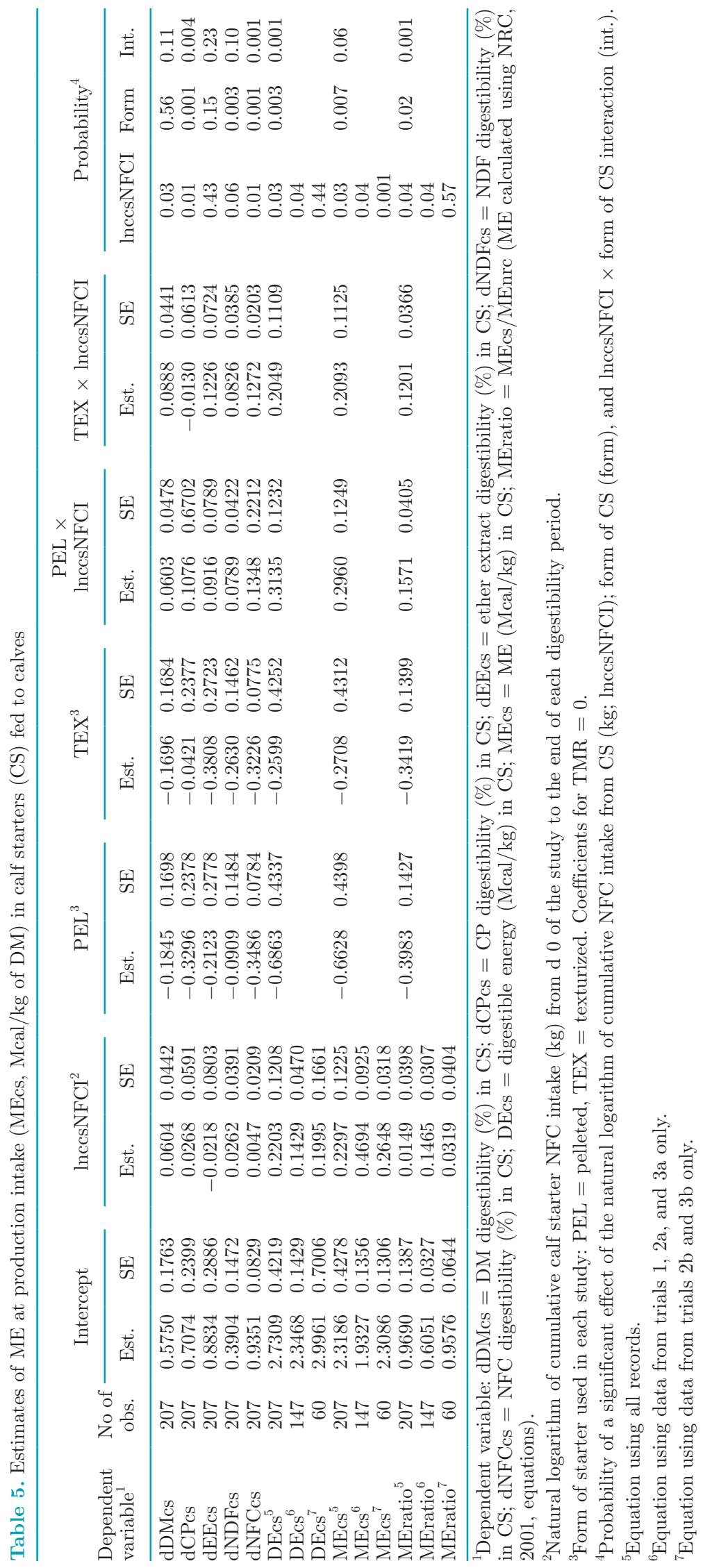



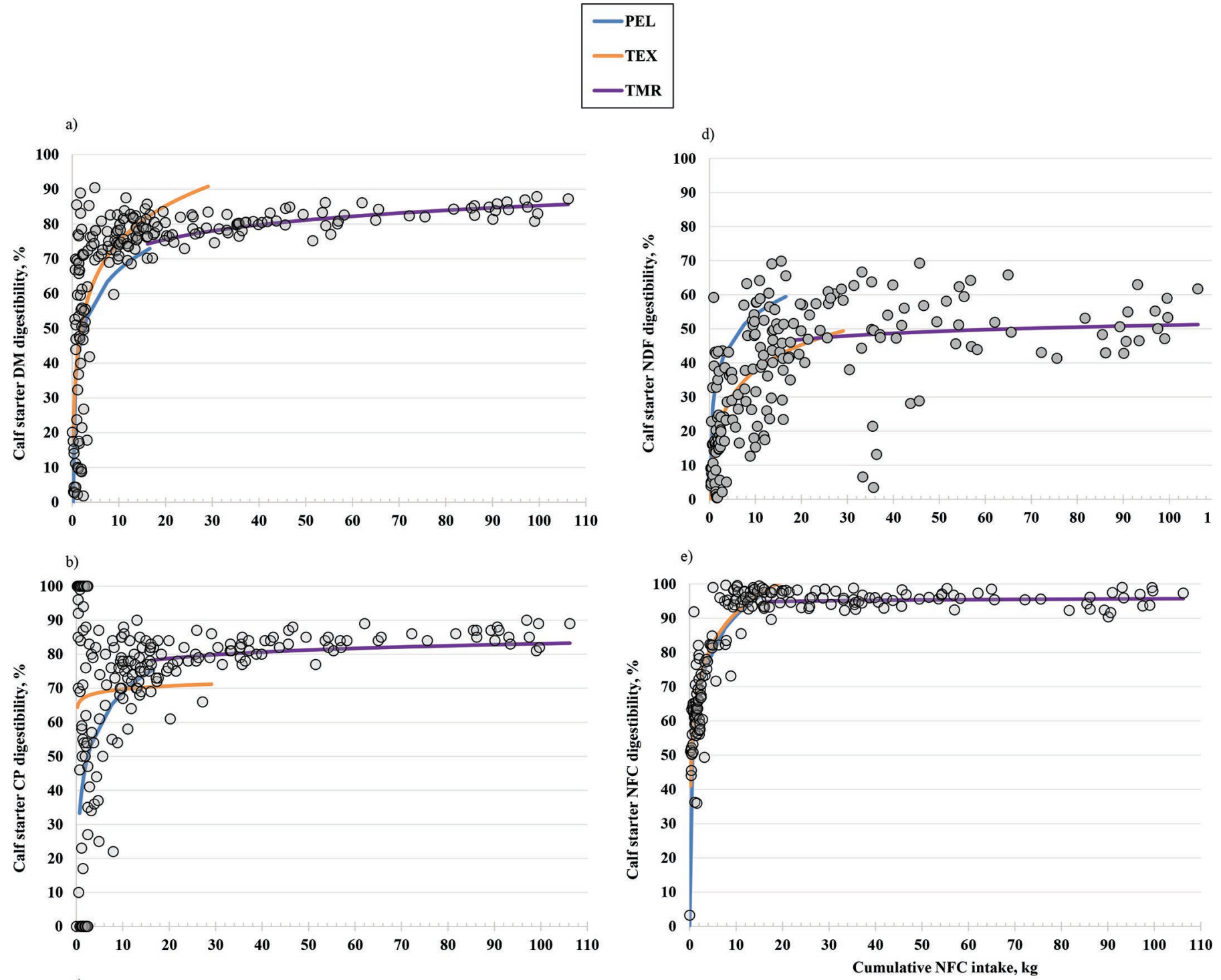

c)

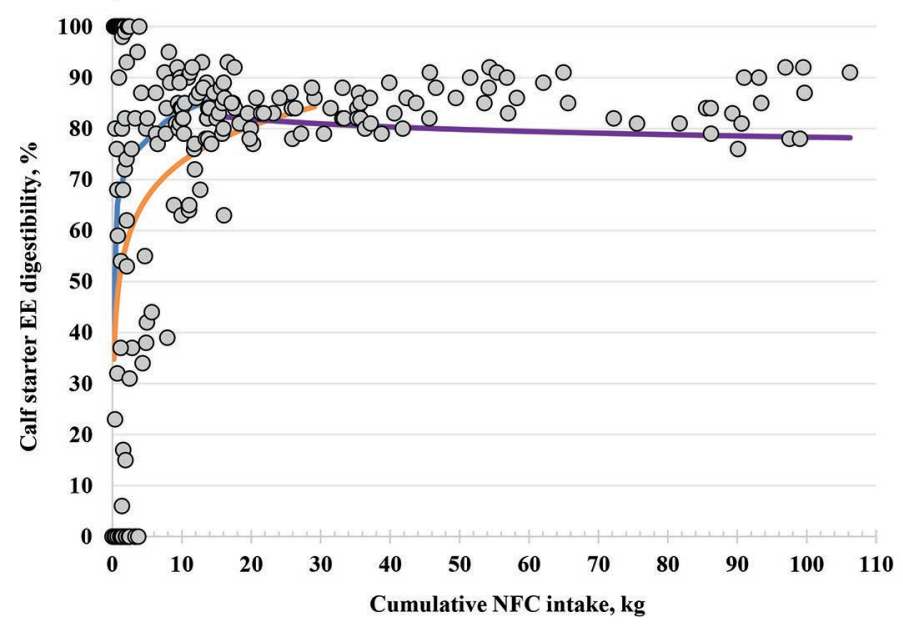

Figure 1. Effect of cumulative NFC intake from calf starter on calf starter nutrient digestibility in calves fed pelleted (PEL) or textured (TEX) calf starters without or with (TMR) 5\% grass hay. Values are adjusted as described by St-Pierre (2001). Panels a to e: DM, CP, ether extract (EE), NDF, and NFC digestibilities, respectively. 
terion of preparation for weaning, if cumulative intake also contributes to gastrointestinal development and increased digestibility.

Most feeds used in this data set were high-starch, TEX without added hay. Few data in our data set included high fiber by-products, and no diets included forage before 8 wk of age. Further, it is unclear whether inclusion of other types of feeds, including a greater use of forage, would influence these calculations. Also, differences in NFC composition including sugar, starch, and pectins could influence our calculations. For example, Suárez et al. (2006) reported that veal calves consuming diets

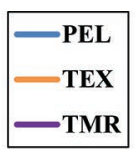

\section{a)}


Figure 2. Effect of cumulative NFC intake from calf starter on calf starter digestible energy (DE) in calves fed pelleted (PEL) or textured (TEX) calf starters without or with (TMR) $5 \%$ grass hay. Values are adjusted as described by St-Pierre (2001). Panel a includes all observations in the data set from d 0 to $112(\mathrm{n}=207)$. Panel b includes only data from d 0 to $56(\mathrm{n}=147)$. containing more NDF consumed more DM compared with calves fed diets containing pectins. Further, rumen fermentation characteristics varied among calves fed diets with carbohydrates derived mainly from starch, NDF, or pectins. More data are warranted to evaluate effects of varying nutrient content, physical form, and feed management on energy predictions.

The MEratio was slightly more correlated with lnccsDMI $(\mathrm{r}=0.817)$ compared with lnccsNFCI $(\mathrm{r}$ $=0.815)$. Therefore, we modeled the effect of lnccsDMI on MEratio during the first $56 \mathrm{~d}$, when MEratio increased to approximately $100 \%$. The equation was

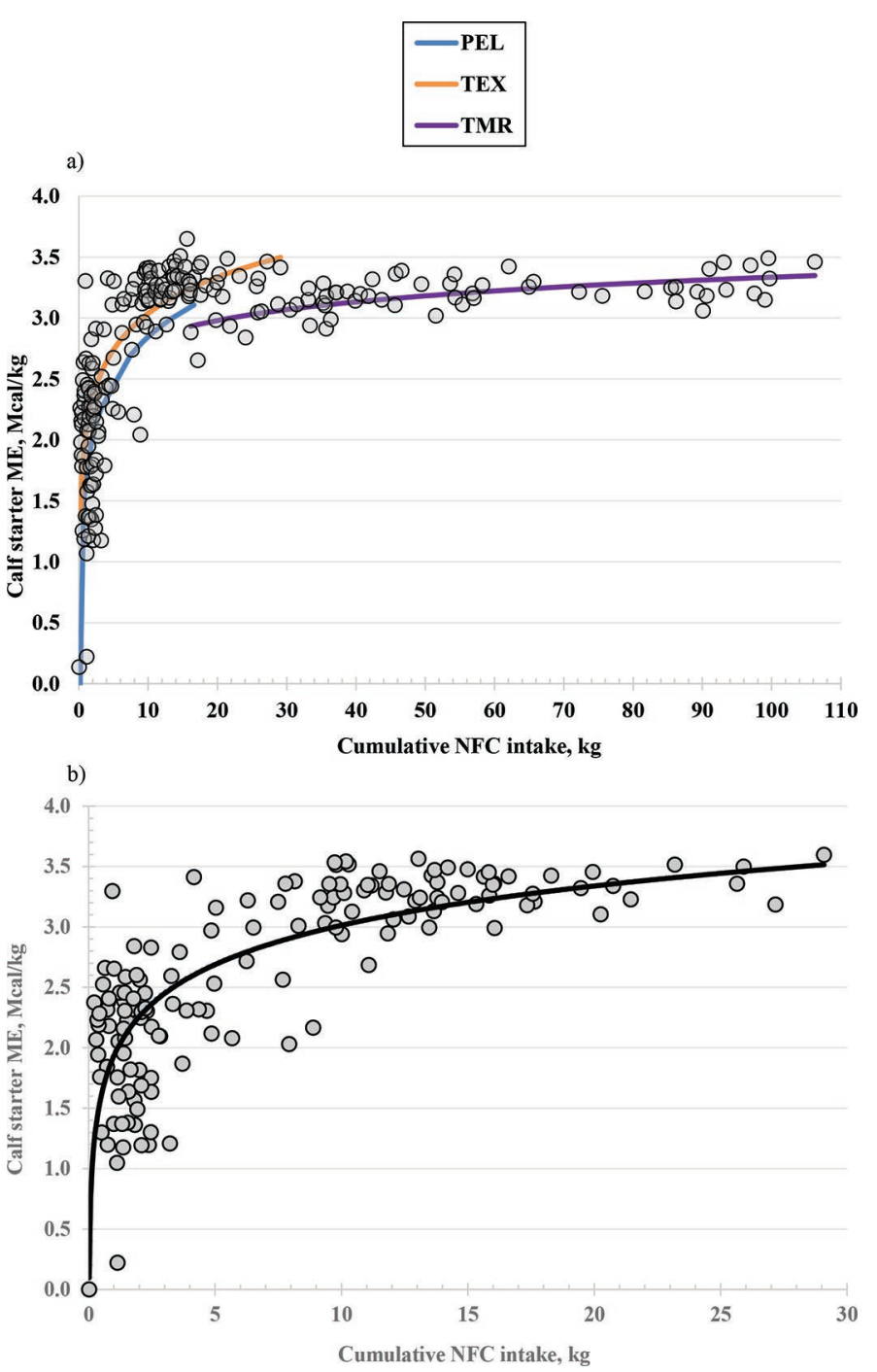

Figure 3. Effect of cumulative NFC intake from calf starter on calf starter ME in calves fed pelleted (PEL) or textured (TEX) calf starters without or with (TMR) $5 \%$ grass hay. Values are adjusted as described by St-Pierre (2001). Panel a includes all observations in the data set from d 0 to $112(\mathrm{n}=207)$. Panel $\mathrm{b}$ includes only data from d 0 to $56(\mathrm{n}=147)$. 
MEratio $=0.5038+0.1486 \times$ lnccsDMI. The standard errors for intercept and slope were 0.05814 and 0.02998 , respectively (Figure 5). Both intercept and slope were significant $(P<0.001)$. The MEratio reached $100 \%$ at $28.5 \mathrm{~kg}$ of cumulative DMI, which is consistent with 15 $\mathrm{kg}$ of cumulative NFC intake, assuming that the percent NFC in CS used in our studies at approximately $53 \%$. Because NFC content of CS may not be known in on-farm situations, the use of cumulative DMI may be a more practical method to estimate the point at which MEcs = MEnrc. The equation could potentially

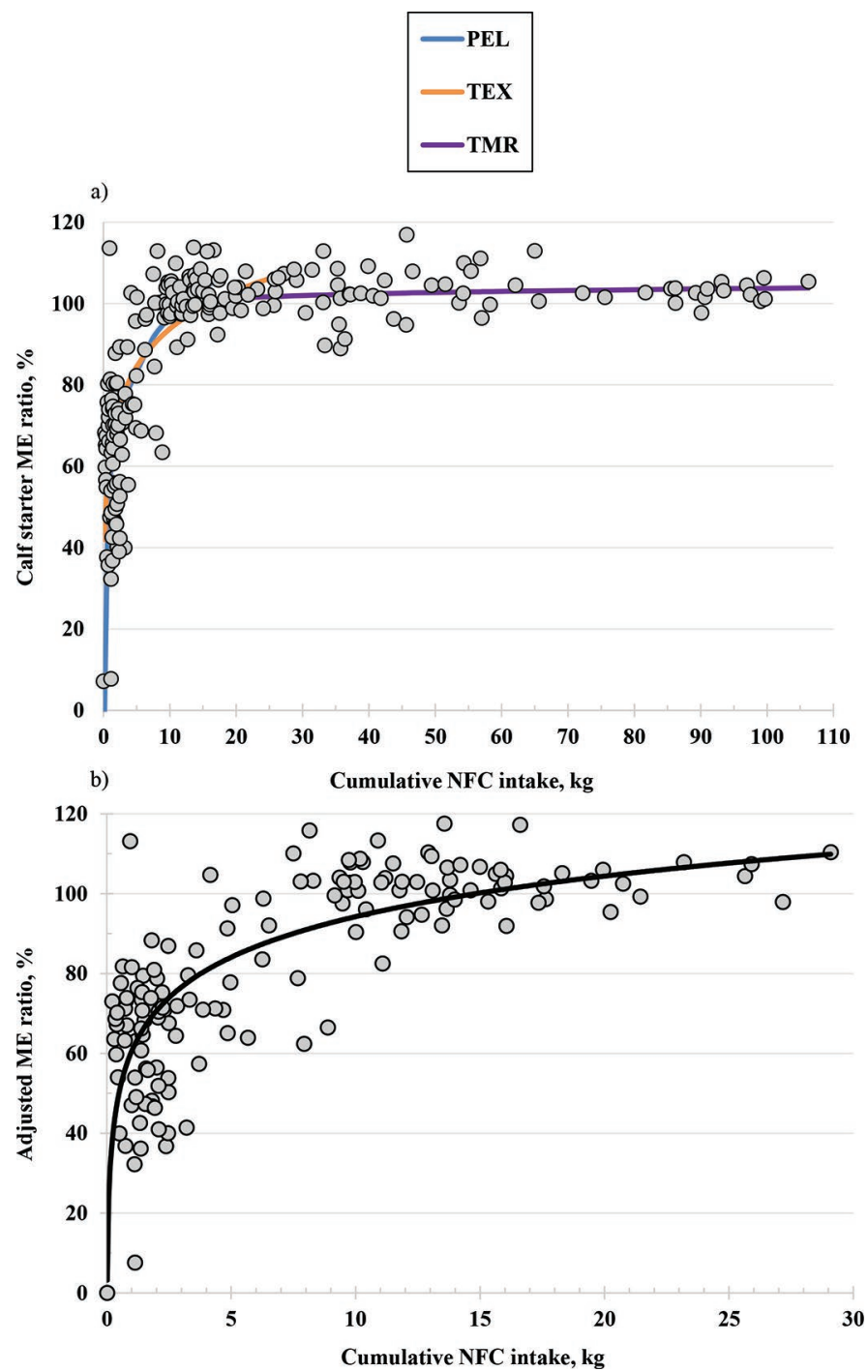

Figure 4. Effect of cumulative NFC intake from calf starter on ratio of calculated ME in calf starter to ME calculated by NRC (2001) in calves fed pelleted (PEL) or textured (TEX) calf starter without or with (TMR) $5 \%$ grass hay. Values are adjusted as described by StPierre (2001). Panel a includes all observations in the data set from d 0 to $112(\mathrm{n}=207)$. Panel $\mathrm{b}$ includes only data from d 0 to $56(\mathrm{n}=147)$.
Table 6. Effect of changing CP digestibility and ether extract in milk replacer on calculated ME in calf starter

\begin{tabular}{lcc}
\hline & \multicolumn{2}{c}{ MEcs $^{1}$} \\
\cline { 2 - 3 } Item & Mean & $\%$ \\
\hline dCPmr & \\
$60 \%$ & & \\
$70 \%$ & 2.55 & 117 \\
$80 \%$ & 2.45 & 112 \\
$81.8 \%$ & 2.24 & 102 \\
$90 \%$ & 2.19 & 100 \\
$100 \%$ & 1.86 & 85 \\
dEEmr & 1.69 & 77 \\
$60 \%$ & & 107 \\
$70 \%$ & 2.34 & 107 \\
$80 \%$ & 2.34 & 107 \\
$90 \%$ & 2.33 & 105 \\
$96.8 \%$ & 2.30 & 100 \\
$100 \%$ & 2.19 & 94 \\
\hline
\end{tabular}

${ }^{1} \mathrm{MEcs}=\mathrm{ME}(\mathrm{Mcal} / \mathrm{kg}$ of DM) in calf starter.

${ }^{2}$ Digestibility of $\mathrm{CP}$ in milk replacer. Mean $\mathrm{dCPmr}=81.8 \%$ was used in model development.

${ }^{3}$ Digestibility of ether extract in milk replacer. Mean dEEmr $=96.8 \%$ was used in model development.

be used to discount MEnrc and allow prediction of the actual ME available to the calf using cumulative DMI.

One criticism of our approach was the need to partition $\mathrm{CP}$ and EE digestibility between MR and CS before weaning. Errors in estimates of MR digestibility would affect prediction of dCPcs and dEEcs and influence prediction of MEcs before weaning. Constant values for dCPmr and dEEmr (81.8 and $96.8 \%$ of DM,

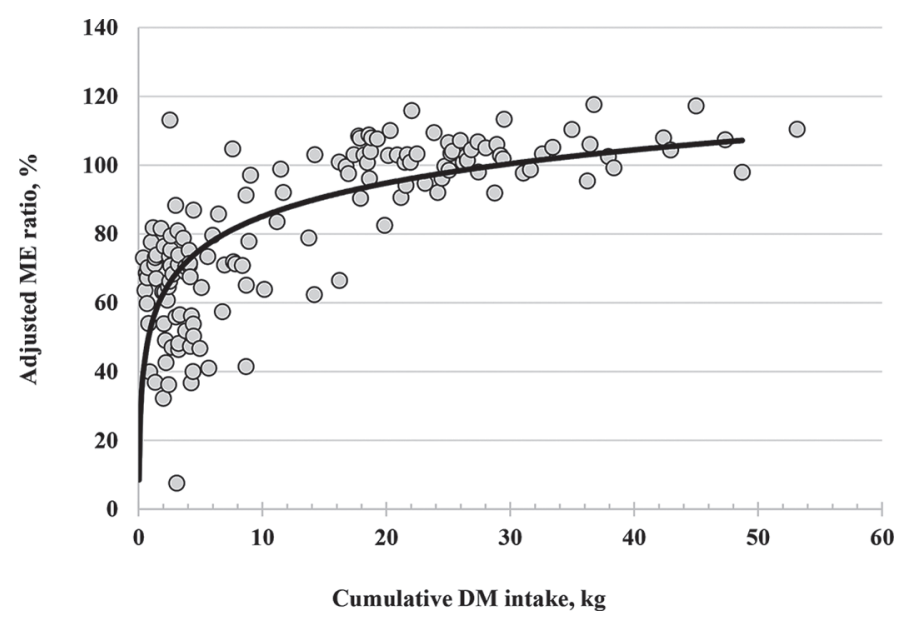

Figure 5. Effect of cumulative DMI from calf starter on ratio of calculated ME in calf starter to ME calculated by NRC (2001) for the first $56 \mathrm{~d}$ of the trial $(\mathrm{n}=147)$. Model was ME ratio $=0.5038+$ $0.1486 \times$ natural logarithm of cumulative DMI $(\mathrm{kg})$. Standard errors for intercept and slope were 0.05814 and 0.02998 , respectively. Effect of form of diet was not included in the model. 
respectively) were used in model development. Table 6 demonstrates effect of changing digestibility of $\mathrm{CP}$ and $\mathrm{EE}$ in MR on calculated MEcs before weaning. Generally, as digestibility of $\mathrm{CP}$ or $\mathrm{EE}$ was reduced in $\mathrm{MR}$, calculated energy values in CS increased, as the model required that digestibility of $\mathrm{CP}$ or $\mathrm{EE}$ in $\mathrm{CS}$ would increase to maintain TTD of $\mathrm{CP}$ or EE. Although partitioning $\mathrm{CP}$ and $\mathrm{EE}$ between $\mathrm{CS}$ and $\mathrm{MR}$ adds a potential source of error to these calculations, we believe the effects on the overall results were not large. However, additional data are needed to corroborate or refute this assumption.

\section{CONCLUSIONS}

Before weaning, calves obtain less energy from CS than predicted by existing NRC (2001) models. Development of the gastrointestinal system to efficiently digest nutrients, but particularly carbohydrates, is required. Cumulative intake of NFC from CS appears to be a critical factor in the development of digestibility of NDF and NFC and, thus, DE and ME in CS. In this study, when calves consumed a minimum of $15 \mathrm{~kg}$ of cumulative NFC from CS, digestibility of nutrients improved to the point at which MEcs were similar to MEnrc, suggesting that gastrointestinal maturation developed sufficiently to allow calves to extract energy from CS. Accumulated intake of $15 \mathrm{~kg}$ of NFC from CS would equate to $30 \mathrm{~kg}$ of a $50 \%$ NFC starter or $60 \mathrm{~kg}$ of NFC from a $25 \%$ NFC starter. Adjustment of NRC calculations of energy values of CS for calves from birth to approximately 4 mo of age appears warranted.

\section{ACKNOWLEDGMENTS}

The authors gratefully acknowledge the input of the farm crew at the Nurture Research Center and assistance and advice of A. Nayeri and M. Baldin (Provimi) in design and data interpretation. The research was wholly funded by Provimi North America, a division of Cargill Animal Nutrition.

\section{REFERENCES}

Baldwin, R. L., K. R. McLeod, J. L. Klotz, and R. N. Heitmann. 2004. Rumen development, intestinal growth and hepatic metabolism in the pre- and postweaning ruminant. J. Dairy Sci. 87:(E. Suppl.):E55-E65.

Blum, J. W. 2006. Nutritional physiology of neonatal calves. J. Anim. Physiol. Anim. Nutr. (Berl.) 90:1-11.

Chapman, C. E., P. S. Erickson, J. D. Quigley, T. M. Hill, H. G. Bateman II, F. X. Suarez-Mena, and R. L. Schlotterbeck. 2016. Effect of milk replacer program on calf performance and digestion of nutrients with age of the dairy calf. J. Dairy Sci. 99:2740-2747.
Dennis, T. S., F. X. Suarez-Mena, T. M. Hill, J. D. Quigley, and R. L. Schlotterbeck. 2017. Effects of egg yolk inclusion, milk replacer feeding rate, and low-starch (pelleted) or high-starch (texturized) starter on Holstein calf performance through 4 months of age. J. Dairy Sci. 100:8995-9006.

Dennis, T. S., F. X. Suarez-Mena, T. M. Hill, J. D. Quigley, R. L. Schlotterbeck, and L. Hulbert. 2018. Effect of milk replacer feeding rate, age at weaning, and method of reducing milk replacer to weaning on digestion, performance, rumination, and activity in dairy calves to 4 months of age. J. Dairy Sci. 101:268-278.

Greenwood, R. H., J. L. Morrill, and E. C. Titgemeyer. 1997. Using dry feed intake as a percentage of initial body weight as a weaning criterion. J. Dairy Sci. 80:2542-2546.

Guilloteau, P., T. Corring, R. Toulec, and J. Robelin. 1984. Enzyme potentialities of the abomasum and pancreas of the calf. I. Effect of age in the preruminant. Reprod. Nutr. Dev. 24:315-325.

Guilloteau, P., R. Zabielski, and J. W. Blum. 2009. Gastrointestinal tract and digestion in the young ruminant: Ontogenesis, adaptations, consequences and manipulations. J. Physiol. Pharmacol. 60(Suppl. 3):37-46.

Harmon, D. L., R. M. Yamka, and N. A. Elam. 2004. Factors affecting intestinal starch digestion in ruminants: A review. Can. J. Anim. Sci. 84:309-318.

Hibbs, J. W., H. R. Conrad, W. D. Pounden, and N. Frank. 1956. A high roughage system for raising calves based on early development of rumen function. 6. Influence of hay to grain ratio on calf performance, rumen development, and certain blood changes. J. Dairy Sci. 39:171-179.

Hill, T. M., H. G. Bateman II, J. M. Aldrich, and R. L. Schlotterbeck. 2010. Effect of milk replacer program on digestion of nutrients in dairy calves. J. Dairy Sci. 93:1105-1115.

Hill, T. M., J. D. Quigley, H. G. Bateman II, F. X. Suarez-Mena, T. S. Dennis, and R. L. Schlotterbeck. 2016a. Effect of milk replacer program on calf performance and digestion of nutrients in dairy calves to 4 months of age. J. Dairy Sci. 99:8103-8110.

Hill, T. M., J. D. Quigley, F. X. Suarez-Mena, H. G. Bateman II, and R. L. Schlotterbeck. 2016b. Effect of milk replacer feeding rate and functional fatty acids on dairy calf performance and digestion of nutrients. J. Dairy Sci. 99:6352-6361.

Khan, M. A., A. Bach, D. M. Weary, and M. A. G. von Keyserlingk. 2016. Invited review: Transitioning from milk to solid feed in dairy heifers. J. Dairy Sci. 99:885-902.

Morrill, J. L., W. E. Stewart, R. J. McCormick, and H. C. Fryer. 1970. Pancreatic amylase secretion by young calves. J. Dairy Sci. 53:72-78.

Nozière, P., I. Ortigues-Marty, C. Loncke, and D. Sauvant. 2010. Carbohydrate quantitative digestion and absorption in ruminants: From feed starch and fibre to nutrients available for tissues. Animal 4:1057-1074.

NRC. 2001. Nutrient Requirements of Dairy Cattle. 7th rev. ed. Natl. Acad. Sci., Washington, DC.

Quigley, J. D., III. 1996. Influence of weaning method on growth, intake, and selected blood metabolites in Jersey calves. J. Dairy Sci. 79:2255-2260.

Quigley, J. D., T. M. Hill, T. S. Dennis, F. X. Suarez-Mena, and R. L. Schlotterbeck. 2018. Effects of feeding milk replacer at 2 rates with pelleted low-starch or texturized high-starch starters on calf performance and digestion. J. Dairy Sci. 101:5937-5948.

Quigley, J. D., W. Hu, J. R. Knapp, T. S. Dennis, F. X. Suarez-Mena, and T. M. Hill. 2019. Estimates of calf starter energy affected by consumption of nutrients. 1. Evaluation of models to predict changing digestion. J. Dairy Sci. 102:2232-2241. https://doi.org/ 10.3168/jds.2018-15354.

Sander, E. G., R. G. Warner, H. N. Harrison, and J. K. Loosli. 1959. The stimulatory effect of sodium butyrate and sodium propionate on the development of rumen mucosa in the young calf. J. Dairy Sci. 42:1600-1605.

St-Pierre, N. R. 2001. Invited Review: Integrating quantitative findings from multiple studies using mixed model methodology. J. Dairy Sci. 84:741-755. 
Stobo, I. J. F., J. H. B. Roy, and H. J. Gaston. 1966. Rumen development in the calf. I. The effect of diets containing different proportions of concentrates to hay on rumen development. Br. J. Nutr. 20:171-188.

Suárez, B. J., C. G. Van Reenen, G. Beldman, J. van Delen, J. Dijkstra, and W. J. J. Gerrits. 2006. Effects of supplementing concentrates differing in carbohydrate composition in veal calf diets: I. Animal performance and rumen fermentation characteristics. J. Dairy Sci. 89:4365-4375.

Terré, M., M. Devant, and A. Bach. 2007. Effect of level of milk replacer fed to Holstein calves on performance during the preweaning period and starter digestibility at weaning. Livest. Sci. 110:82-88.
Van Keulen, J. V., and B. A. Young. 1977. Evaluation of acid insoluble ash as a natural marker in ruminant digestibility studies. J. Anim. Sci. 44:282-287.

Warner, R. G., W. P. Flatt, and J. K. Loosli. 1956. Dietary factors influencing the development of the ruminant stomach. J. Agric. Food Chem. 4:788-792.

Zabielski, R., I. Le Huërou-Luron, and P. Guilloteau. 1999. Development of gastrointestinal and pancreatic functions in mammalians (mainly bovine and porcine species): Influence of age and ingested food. Reprod. Nutr. Dev. 39:5-26. 